\title{
O valor das línguas na realidade de ensino- aprendizagem em Cabo Verde
}

\section{The value of languages in the teaching-learning reality in Cape Verde}

\author{
Gildaris Ferreira PANDIM*
}

\begin{abstract}
RESUMO: Este artigo registra um panorama a propósito de algumas das medidas político-educacionais empreendidas no que toca ao ensino do português enquanto língua oficial e nãomaterna na realidade africana. Atenta especificamente à situação sociolinguística de Cabo Verde, cuja língua materna é um fator de diversidade a ser incluído nessa conjuntura. $\mathrm{O}$ reconhecimento jurídico ou o não reconhecimento das línguas faladas numa nação orienta seus estatutos na sociedade, contribuindo para valorações positivas ou negativas. Considera-se que a língua permite o desenvolvimento psíquico e permeia os relacionamentos interacionais. Ao ser alfabetizado num idioma nãomaterno, questiona-se o processo de construção da identidade social do aprendiz, na relação com o ambiente escolar, com sua própria língua e com a língua do outro. $\mathrm{O}$ artigo objetiva demonstrar, para a realidade em estudo, que a interpenetração da língua e da cultura na sociedade dá-se

ABSTRACT: This article records a scenario about some of the politicaleducational measures undertaken with regard to Portuguese teaching as an official and non-native language in the African reality. It pays attention to the socio-linguistic situation of Cape Verde, which mother tongue is a factor of diversity to be included in this conjuncture. The legal recognition or nonrecognition of the spoken languages in a nation guides its statutes in society, contributing to positive or negative valuations. Language is considered to allow psychic development and permeate interactional relationships. Being literate in a non-native language, one wonders how the process of building the learner's social identity takes place in relation to the school environment, its own language and the language of others. The article aims to demonstrate, for the reality under study, that the interpenetration of language and culture in society occurs differently in each of the languages, Cape Verdean and Portuguese.
\end{abstract} diferentemente em cada um dos idiomas, o cabo-verdiano e o português.

PALAVRAS-CHAVE: Valor das línguas. Interpenetração cultural. Segunda língua. Identidade social. Ensino-aprendizagem.

KEYWORDS: Value of languages. Cultural interpenetration. Second language. Social identity. Teaching-learning.

\footnotetext{
* Doutora em Estudos Linguísticos, Universidade de Cabo Verde. ORCID: https://orcid.org/0000-00028218-0126. gildaris@gmail.com
} 


\section{Introdução}

Os contextos de ensino-aprendizagem do português nas realidades onde o idioma é um dos oficiais caracterizam-se por sua diversidade sociolinguística e complexidade cultural, a que se vêm acrescentar valores às línguas nos níveis social, econômico, político, histórico ou afetivo. Enquanto língua pluricêntrica e pluricultural, presente oficialmente em quatro continentes, comporta idiossincrasias próprias a cada uma das culturas. Adquirida como materna, trata-se da língua pela qual o sujeito começa a construir sua identidade social, ou seja, a vivenciar experiências sociais, estabelecendo relações e associações do mundo que o rodeia. Permite-lhe conectar-se com a rede de universos linguístico-discursivos, legitimando sua presença e pertença a uma comunidade ou um grupo social. É nessa língua que se formam as memórias histórico-sociais habitantes do sujeito, constituindo a cultura da qual é parte integrante. Na relação com o outro, a identidade do falante, enquanto construto sóciohistórico, constitui-se, e estará sujeita a constante mutação.

A identidade social constrói-se na e pela interação, possível graças ao processo comunicativo de uma língua, ou seja, ao compreender e interpretar o que o outro diz, identificando ao mesmo tempo as intenções comunicativas de forma a reagir de acordo com o que se solicita no ato enunciativo. O receptor participa de um processo de interpretação cujos desafios para devida compreensão não se resumem apenas a competências linguísticas.

O corrente artigo aplica-se à realidade cabo-verdiana, onde o português é única língua oficial, segunda língua (L2) e o cabo-verdiano é língua materna (LM), primeira língua (L1), vivo na oralidade e na escrita informal, embora não aprendido nas escolas. Parte-se do pressuposto que no falante, depositam-se as línguas presentes numa comunidade, cujo contato é inevitável em locais onde as línguas oficiais e nacionais diferem-se. Nos casos dos países africanos de língua oficial portuguesa (PALOP), sendo o português oficialmente língua de escolarização e, consequentemente, de 
letramento $^{1}$, porém não materna, qual relação se estabelece entre o aprendiz e as línguas? Em que medida há aceitação ou rejeição da língua portuguesa? Como as políticas das línguas (des)favorecem as construções identitárias? Que valor é atribuído a esses idiomas? Subjacente a esses questionamentos, encontra-se a complexa relação entre a língua materna, o contexto-fonte do aprendiz, e a língua não-materna, o contexto-alvo ${ }^{2}$.

Este trabalho organiza-se a partir de três objetivos: 1) descrever e problematizar a vivência em cada uma das línguas, português e cabo-verdiano, nos planos cultural e histórico (BENVENISTE, 1966; LÉVI-STRAUSS, 1962); 2) refletir sobre o dever do Estado de reconhecimento jurídico das línguas, trabalhando para sua concretização (SIBILLE, 2002); 3) apontar eventuais reflexos no processo de ensino-aprendizagem decorrentes dos estatutos e dos valores das línguas na realidade em estudo (CALVET, 2002; LOPES, 2016).

\section{Língua como vivência cultural e histórica}

Benveniste (1966, p. 29) sustenta que não se pode conceber linguagem, língua e cultura separadamente, uma vez que a língua é um dos meios pelos quais o homem assimila a cultura, perpetuando-a ou transformando-a. Parafraseando o referido autor

\footnotetext{
1 Em Cabo Verde, foram inicialmente estabelecidas metas governamentais em parceria com a Organização das Nações Unidas para erradicação do analfabetismo. No último relatório ODM da ONU, publicado em 2015, a taxa de alfabetização do público feminino adulto (maiores de 15 anos) passou 67,2\% (2000) para 83,4\% (2013); para o público masculino adulto (maiores de 15 anos), mesmo período, respectivamente, as taxas foram de $83,5 \%$ e $91,0 \%$. Resta ainda o objetivo de atingir o letramento, ou seja, a criação e reforço de condições e práticas que visem a leitura e a escrita como forma de integração na sociedade, e não simplesmente a alfabetização, que se restringe à leitura e à escrita exclusivamente. A esse propósito, consultar o Relatório ODM, disponível em https://www.un.cv/files/Relatorio\%20ODM\%20Julho\%202015.pdf, acesso em: 30 out. 2019, e também o artigo "O bilinguismo e a problemática da diglossia no processo de letramento: o caso de Cabo Verde e suas diásporas" (LOPES, 2011).

2 Entende-se que, na aprendizagem de uma língua não-materna, o contexto-alvo e o contexto-fonte agem como fatores interculturais. Ao estar mais consciente do contexto-fonte, das implicações enunciativas próprias da L1, o aprendiz terá a tendência de estar mais atento ao contexto-alvo na L2 (SERRANI-INFANTE, 2002).
} 
(1966, p. 12-28), a faculdade inerente ao ser humano de representação e compreensão da realidade ou da experiência através de um signo implica a categorização e subsequente organização dessa realidade pelo pensamento. Esse se traduz pela linguagem, materializada pela língua, uma das principais fontes de conhecimento sobre a cultura de um povo.

À medida que um indivíduo, integrado numa sociedade, cresce e adquire competências para a realização de tarefas intelectuais mais complexas, paralelamente interioriza reflexos culturais próprios do ambiente que o circunda. A cultura é compreendida como conjunto(s) de valores de um grupo ou sociedade ${ }^{3}$, que, por sua vez, tende a classificar e comparar dados, situações, acontecimentos para poder entender e dar sentido àquilo que é novo (LÉVI-STRAUSS, 1962, p. 17). Para isso, usase língua, cujos processos comunicativos podem abarcar conteúdos e aspectos culturais marcantes.

A relação intercultural e a interpenetração da língua portuguesa no contexto cabo-verdiano, enquanto língua oficial, difere-se evidentemente daquela do caboverdiano, vivo na oralidade. Estrategicamente, enquanto país sediador do programa da presidência pro-tempore da CPLP, período compreendido entre 2019 e 2020, sob o lema "As pessoas, a cultura, os oceanos", o português continua a assumir o papel e o lugar de língua oficial, única de escolarização, embora não-materna. O interesse advém dos percursos e laços históricos evidentes com o mundo em língua portuguesa; das impulsionadoras relações político-econômicas com a Europa; da substancial projeção internacional, que se concretiza com programas nacionais de fomento em diversos âmbitos, na educação, na saúde, na formação profissional-técnica, no meioambiente ou até mesmo na construção civil.

\footnotetext{
${ }^{3} \mathrm{O}$ tema foi amplamente desenvolvido em disciplinas como a Antropologia, a Etnologia e a Filosofia (cf. CASSIRER, 1972; LÉVI-STRAUSS, 1958, 1973; LINTON, 1977; LOMBARD, 1994; POIRIER, 1968, 1978).
} 
Amélia Mingas, no Simpósio sobre o tema “Interpenetração da Língua e Culturas de/em Língua Portuguesa na CPLP", realizado em março de 2008 pelo Instituto Internacional da Língua Portuguesa (IILP) e a Associação das Universidades de Língua Portuguesa, destacou que [no contexto da CPLP] “a língua portuguesa é um valor construído e em construção, com contribuições variadas de múltiplas formas de expressão e de representação e que coloca à comunidade política que a utiliza, a necessidade de a enquadrar no sistema de valores".

$\mathrm{Na}$ realidade cabo-verdiana, ao português reserva-se o lugar de língua da comunicação escrita - comunicação social, literatura, legislações, documentos administrativos. Brito-Semedo, por exemplo, aponta que "escritores como Corsino Fortes [1933-2015], em sua época, [...] assumiram o português como uma língua literária própria, interiorizando-o sem complexos, trabalhando-o no máximo da sua potencialidade" (2010, p. 175). Na oralidade, os contextos de uso da língua portuguesa nos meios formais têm alterado ao longo dos anos, resultado direto da independência política do país e das medidas com o sentido de integrar, na vida social, o caboverdiano. Nas divisões públicas, nas universidades ${ }^{4}$, nas escolas, e mesmo nas sessões plenárias a língua cabo-verdiana vem cada vez mais conquistando seu espaço, em termos de uso propriamente e de estudo, de descrição e de investigação ${ }^{5}$. Se, por um lado, trata-se de um processo de autonomia da nação, que passa pela liberdade e defesa linguísticas, por outro lado, essa integração não se dá de forma institucionalizada e, sobretudo, reflete uma situação in vivo.

Cumpre destacar que, no cenário atual e na prática, os estatutos de cada uma das línguas, português e cabo-verdiano, não são idênticos, não obstante o artigo 9º da

\footnotetext{
${ }^{4}$ A título de exemplo, na Universidade de Cabo Verde, única pública do país, o curso de graduação de Letras intitula-se "Línguas, Literaturas e Culturas: Estudos Cabo-verdianos e Portugueses" e propõe uma dupla formação, em português e em cabo-verdiano. Na mesma universidade, desde 2010, propõese o Mestrado de Crioulística e Língua Cabo-verdiana.

${ }^{5}$ Citamos, por exemplo, a Proposta de Bases do Alfabeto Unificado para a Escrita do Cabo Verdiano (PRAIA, 1994); e a Proposta de Bases para a Oficialização da Língua Cabo-verdiana (PRAIA, 2015).
} 
Constituição da República de Cabo Verde (4ª edição, 2a revisão ordinária, 2010) rezar que, para além do português ser língua oficial, o Estado promove as condições para a oficialização da LM cabo-verdiana, em paridade com a língua portuguesa e ainda que todos os cidadãos nacionais têm o dever de conhecer as línguas oficiais e o direito de usá-las.

No plano cultural, o português interpenetra os conjuntos de normas, valores e conceitos que caracterizam e identificam o "ser cabo-verdiano". As representações e

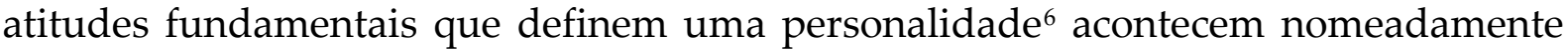
com o compartilhamento da LM. Manuel Veiga, ao discorrer sobre a afirmação e a valorização do crioulo, reitera que "as tradições orais do nosso povo, apesar de proibidas, em algumas manifestações, fizeram do crioulo a língua por excelência de comunicação e o espaço privilegiado de resistência cultural” (2007, p. 40). Exemplos típicos são as letras de música, as tradições orais, a poesia, o cotidiano das instituições, que vivem em grande parte em língua cabo-verdiana. Há um comportamento linguístico coletivo, com suas implicações sociais, psicológicas, políticas e culturais. A L1, enquanto materna, particulariza e marca a identidade social, reforçando a personalidade cultural, ao passo que o português, como oficial e L2, estabelece a ligação com outras comunidades, contribui no processo de organização social, concretiza a aprendizagem de conhecimentos especializados.

As relações e os usos de cada uma das línguas não acontecem, contudo, de forma tão harmoniosa. Visto as vivências culturais e históricas inscritas em cada uma das línguas diferirem-se, com a imposição da L2 no processo de especialização numa área de conhecimento (por exemplo, em cursos universitários), o aprendiz vê-se confrontado frequentemente no processo de ensino-aprendizagem em L2, à falta de conhecimento de conceitos mais difundidos em sociedades outras, onde aconteceram mudanças socioeconômicas importantes, como a industrialização ou a urbanização

\footnotetext{
${ }^{6}$ De acordo com Houis (1968), supramencionado.
} 
intensiva. Isso pode refletir no plano lexical - uma das competências mais solicitadas na aprendizagem de uma língua não-materna, mas sobretudo as maneiras de construção das significações também divergem-se, e tornam-se desprovidas de sua carga efetiva no outro idioma, provocando o que Revuz qualifica de um verdadeiro confronto:

Esse confronto entre a primeira e a segunda língua nunca é anódino para o sujeito e para a diversidade de estratégias de aprendizagem (ou de não aprendizagem) de uma segunda língua, que se pode observar quando se ensina numa língua e se explica, sem dúvida, em grande parte pelas modalidades desse confronto (REVUZ, 1998, p. 215, grifo da autora).

Lidar com a alteridade, com a estranheza da outra língua, com sua própria flexibilidade psíquica, sabendo que não gozará do conforto afetivo instaurado na L1, da qual precisará provavelmente se afastar para dominar a L2, construindo um novo eu, são alguns dos elementos que podem desestabilizar o aprendiz. Certamente que, se transpostos esses obstáculos, mesmo que não completamente, porém o suficiente para conseguir comunicar-se na L27, o aprendiz terá avançado, "mesmo que modestamente, em relação aos discursos sociais e familiares que nos perseguem, nos constroem e nos coagem"; terá igualmente enfrentado "um espaço silencioso no qual é preciso se inventar para dizer eu" (REVUZ, 1998, p. 228-229). Terá ainda confrontado outra vivência, que talvez não se assemelhe àquela da LM.

\section{0 valor das línguas}

Nos contextos plurilíngues, os conflitos linguísticos decorrem em grande parte dos valores atribuídos às línguas em contato. As situações de diglossia, um fenômeno

\footnotetext{
${ }^{7}$ Há diversas discussões e definições sobre o que é ser bilíngue (ver, por exemplo, ZIMMER; FINGER; SCHERER, 2008). Para fins deste trabalho, entendemos que bilíngue é quem domina duas línguas, em níveis de competência e graus não necessariamente idênticos.
} 
social, podem perdurar numa sociedade por séculos, como é o caso de Cabo Verde. Em constante evolução, a diglossia provoca nos membros de uma comunidade comportamentos valorativos ou depreciativos em relação às variedades em uso, que, assim como qualquer idioma, comportam valores: afetivos, culturais, comerciais, econômicos, políticos, históricos, identitários, ideológicos, sociais. Tendo já suscitado interesse e atenção de pesquisadores em sociolinguística, mas também outras ciências correlacionadas (antropologia, sociologia, ciências da educação, psicologia), o valor das línguas condiciona seus lugares numa sociedade, atingindo os grupos sociais.

As atitudes linguísticas influenciam o comportamento linguístico, calcado num comportamento social instaurado na sociedade face ao que se considera como norma:

Existe na sociedade o que poderíamos chamar de olhares sobre a língua, de imagens da língua, em uma palavra, normas que podem ser partilhadas por todos ou diferenciadas segundo certas variáveis sociais (...) e que geram sentimentos, atitudes, comportamentos diferenciados (CALVET, 2002, p. 72, grifo do autor).

Falar a forma prestigiada legitima a posição do falante perante o grupo social, sendo sua fala avaliada não só em termos linguísticos, mas principalmente sociais. Argumentando que o contato entre línguas provoca um problema de comunicação social, Calvet (2002, p. 51-55) analisa o caso das línguas crioulas, e entende que seu modo particular de emergência não legitima sua condição de língua inferior, com frequência atribuída socialmente. Acrescenta ainda que:

Por longo tempo desprezados, considerados como formas inferiores e exatamente por isso sem acesso às funções oficiais (ensino, administração), hoje os crioulos são promovidos à posição de língua oficial (nas ilhas Seychelles e no [sic] Cabo Verde) e utilizados em caráter experimental no ensino (nas Antilhas francesas e no Haiti) (CALVET, 2002, p. 55, grifo nosso). 
Embora se constate o objetivo de paridade dos estatutos das línguas portuguesa e cabo-verdiana, conforme verificado na constituição do país, criando políticas e condições que visem o acesso a um bilinguismo aditivo e horizontal ${ }^{8}-$ pressupondo nesse caso que a escolarização aconteceria em ambas as línguas - é forçoso admitir, atualmente, que há poucas iniciativas nesse sentido. A situação diglóssica ainda persiste, pois o cotidiano acontece em grande parte em L1, como por exemplo, na comunicação social, posto que muitos programas radiofônicos e mesmo televisivos são transmitidos no idioma nacional ou nas instituições privadas e públicas, cujo atendimento se dá majoritariamente em LM. O português, língua minoritária, cujo domínio é mais preponderante em grupos sociais favorecidos, constitui uma das formas de se demonstrar poder linguístico-intelectual, financeiro ou educacional, e permanece restrito a situações formais de uso.

Sibille (2002), ao discorrer sobre as línguas minoritárias na realidade francesa, sobretudo aquelas regionais, como a bretã ou a corsa, não integradas sistematicamente aos currículos das instituições de ensino, defende que no plano cultural, uma língua minoritária vale por (i) veicular um saber na sociedade; (ii) agregar diversidade à sociedade; (iii) constituir um patrimônio, uma memória história para um povo. Embora o contexto sociolinguístico cabo-verdiano seja diferente, dado que o português, único oficial, é minoritário, e o cabo-verdiano é majoritário e linguisticamente dominante (ainda que não ensinado nas instituições escolares), a reflexão teórico-filosófica que preside a categorização proposta pelo autor serve ao caso de Cabo Verde para a explicitação dos valores das línguas.

\footnotetext{
${ }^{8}$ Entende-se que a aprendizagem do português acontece, em grande parte, a partir dos 6 anos de idade, momento da escolarização, tendo já o aprendiz adquirido a língua materna. Dessa forma, considera-se que se trata de um bilinguismo sequencial (aquisição de uma língua e após a outra), contudo os contextos de aprendizagem diferem-se consideravelmente. Ainda, há uma situação atualmente de bilinguismo vertical, uma vez que os estatutos das línguas não estão em paridade (cf. FLORY; DE SOUZA, 2009).
} 
A literatura na realidade cabo-verdiana, redigida majoritariamente em português, revela que, assim como em outros países africanos de expressão portuguesa, faz-se necessário dominar o idioma, de forma a atingir maior público, sobretudo aquele de fora. Sem deixar de lembrar a realidade do país, com expressões próprias que denotam particularidades no plano linguístico (semântico ou sintático, por exemplo), escreve-se na língua que se aprendeu na escola, exemplificado por alguns dos autores cabo-verdianos lidos na atualidade: Germano Almeida, Fátima Bettencourt, Arménio Vieira, Jorge Carlos Fonseca, Orlanda Amarílis.

Nas escolas, associa-se com frequência o prestígio, a ascensão social à "norma culta" (entenda-se europeia) do português. À língua cabo-verdiana, reserva-se o lugar do afeto $^{9}$, contudo sem gozar do direito de ser ensinada e aprendida. O lugar do português na realidade cabo-verdiana é assim veiculado pelos grupos sociais mais influentes e intelectualizados, cujo valor que o atribuem permite à L2 manter-se nesta realidade, viabilizando a continuidade da ligação do arquipélago com outros países da CPLP. A falta de medida efetiva para a inserção da LM no meio escolar não fornece os elementos para a devida conscientização do aluno no que tange a sua descrição e suas particularidades, reforçando, por conseguinte as ideias de "que o crioulo é um português malformado ou mal falado" ou ainda, uma qualificação pejorativa bastante recorrente no senso comum, "um dialeto". Todavia, conforme explicitado por linguistas estudiosos do crioulo, entende-se que se trata de uma nova língua, que carece de estudo e prestígio assim como outras:

Em Cabo Verde, foram as crianças que, adoptando como língua materna as variedades básicas da língua segunda faladas pelos

\footnotetext{
${ }^{9}$ A apelação "língua de cultura" também é utilizada, conforme explica Lopes: “(...) continua a prevalecer a Lei de Bases do Sistema Educativo (Lei no 103/III/90 de 29 de dezembro, com as alterações de 18 de outubro de 1999 - Lei no 113/V/99), a qual assume a LP como meio e objecto de ensino e a LCV como "manifestação privilegiada da cultura" a ser valorizada como o objectivo de "reforçar a identidade cultural e de integrar os indivíduos na colectividade em desenvolvimento" (no 2 do Artigo 9o - Educação e identidade cultural)" (LOPES, 2016, p. 362-363).
} 
adultos, no seu processo de aquisição, aceleraram as mudanças, contribuindo para a criação de uma nova língua - um crioulo. Este não resultou de uma evolução nem do português, nem das línguas africanas: foi antes resultado da reestruturação (de uma nova "leitura" e reelaboração) de um material linguístico novo e diferenciado: aquele que os primeiros escravos africanos puderam adquirir e que produziam mais frequentemente, em seu contacto limitado com a língua portuguesa e seus falantes. Esse material, de base portuguesa, continha também formas de expressão e de conteúdo das línguas africanas faladas na comunidade (PEREIRA, 2006, p. 28-29, grifos da autora).

Pereira destaca ainda que ideias (mal) feitas sobre os crioulos apresentam consequências de ordem sociolinguística, linguística e metalinguística:

O facto de os crioulos de base portuguesa terem sido durante muito tempo classificados pelo senso comum como variedades de português mal falado ou afastado da norma levou a que muitos falantes das línguas crioulas interiorizassem a ideia de que falar sua língua, sobretudo em público, era socialmente pouco prestigiante. Para tal, contribuiu também, além das pressões simbólicas, a real repressão linguística a que foram frequentemente sujeitos. Veja-se o caso de Cabo Verde, onde, em 1921, o governo local emitiu uma Portaria proibindo o uso do crioulo em todas as repartições públicas, sob pena de aplicação de sanções disciplinares a quem não a cumprisse (PEREIRA, 2006, p. 40).

$\mathrm{Na}$ realidade cabo-verdiana, prevalece o português no ambiente escolar, oficialmente como L2:

Os Planos de Estudos concebidos no âmbito da reforma de ensino, generalizada no ano lectivo 1994/95 e que se fundam na Lei de Bases, instituem a LP como objeto de ensino adequadas ao seu estatuto (língua segunda) e não de língua materna (...) ao mesmo tempo que destacam a sua importância no quadro das disciplinas do plano de estudos e como meio de ensino, considerando mesmo que o seu deficiente domínio pode ser um dos factores de insucesso escolar (LOPES, 2011, p. 363, grifo nosso). 
Com a falta de estímulo institucional visando uma aprendizagem mais dinâmica e pragmática do idioma, as interferências linguísticas que acontecem da LM em relação à L2 são percebidas como “erros". Sem atentar, institucionalmente, à língua majoritária - falada no cotidiano das relações entre os cabo-verdianos, em quaisquer âmbitos, é inegável que a não-escolarização em sua LM influencia no processo de aprendizagem, em especial no plano metalinguístico. Valorizar e incentivar o bilinguismo horizontal através de ações institucionais incidiria positivamente no letramento, no conhecimento linguístico e mesmo desenvolvimento cognitivo, como já demonstrado nos estudos em psicolinguística (ZIMMER; FINGER; SCHERER, 2008).

Com base no argumento de Sibille (2002) de que as línguas são os elementos que permitem a uma sociedade formar, desenvolver e alimentar continuamente sua memória histórica - condição sine qua non de uma sociedade harmoniosa e democrática - a escolarização em língua portuguesa na realidade cabo-verdiana não é algo negativo, contudo, a partir do momento em que se valoriza e se prestigia a L2, negligenciando a complexidade de um meio caracterizado pela sua pluralidade linguística, incorre-se num esquecimento/apagamento do patrimônio culturallinguístico, formado na L1. Ainda, a comunicação social por parte dos ministérios contribui para a ideia do (não)lugar do cabo-verdiano, enquanto língua de ensino:

O ensino do português é fundamental para o futuro de Cabo Verde. Nós queremos ter recursos altamente qualificados e a língua portuguesa é a língua do conhecimento, é a nossa língua e temos de assumi-la de forma descomplexada.

$[\ldots]$

Nós falamos português há mais de 500 anos em Cabo Verde. Falamos crioulo há mais de 500 anos em Cabo Verde. Devemos tudo fazer para promover o ensino da língua portuguesa10.

\footnotetext{
${ }^{10}$ Parte do discurso do atual Ministro de Relações Exteriores de Cabo Verde, publicado em Observador On Time em 18 de julho de 2019. Disponível em: https://observador.pt/2019/07/18/governo-de-caboverde-defende-importancia-do-ensino-do-portugues-e-sem-complexos/. Acesso em: 09 out. 2019.
} 
Reconhecer a legitimidade de conhecimento, transmissão, ensinoaprendizagem da LM, zelando pela sua efetiva aplicabilidade, constitui uma das tarefas do Estado, posto que constitucionalmente, impõe-se a necessidade de ambas as línguas estarem em paridade. O lugar e o valor das línguas, dessa forma, constroemse certamente na cultura, envolvendo história e identidade, porém o papel do Estado de reconhecimento jurídico das línguas e sua concretização através dos atos revela-se incontornável para evitar, ou pelo menos, minimizar, situações de diglossia. Enquanto isso persistir, o "sentimento complexado" em relação ao português continuará muito provavelmente a existir, além de impactar negativamente no ensino-aprendizagem das línguas, uma vez que "certas línguas têm mais valor que outras". Ainda, na mesma linha de ideias, a noção de valor atribuída ao português na realidade dos países de língua co-oficial portuguesa é legitimada pelo que Faraco (2016, p. 239) intitula de "topos do orgulho", que afinal nada mais representa do que uma "construção imaginária compensatória do senso [comum] de ser menor do que se deseja". Com efeito, o autor sustenta que:

Embora qualquer língua, por critérios puramente linguísticos, seja equivalente a qualquer outra em termos de plenitude formal, seu estatuto político pode variar em razão de circunstâncias históricas e socioculturais. São, portanto, duas distintas escalas de valores: a plenitude formal (critério puramente linguístico) iguala todas as línguas; as distintas realidades socioeconômicas, históricas e culturais (critérios não linguísticos) hierarquizam as línguas (FARACO, 2016, p. 239).

Numa análise muito lúcida e concreta da história sociopolítica da língua portuguesa, o pesquisador critica o quanto o discurso sobre a língua ainda é exaltado e idealizado, no âmbito político e midiático, destacando que:

Não há espaço para dar visibilidade aos ressentimentos e conflitos sociolinguísticos que refletem ainda a divisão social que o colonialismo 
impôs às sociedades africanas e que, no fundo, é sinalizada pelas diferentes formas como a língua funciona socialmente, ou seja, os estratos que a têm como língua materna, os que a falam como segunda língua e os que não a conhecem (FARACO, 2016, p. 317).

Severo (2016), ao discorrer sobre a processo colonial de discursivização das línguas na América, entende que por nascerem no contexto colonial, constituem as formas de expressão das "práticas colonizadoras e modernizadoras, como a cristianização, a folclorização, a cientificização e a escolarização" (2016, p. 11). Por conseguinte, "não por acaso, em contexto africano, o letramento e a educação linguística assumem um papel ambivalente, como instrumentos de controle e/ou como formas de emancipação social (SEVERO, 2016, p. 12, apud MAKONI, 2003).

Não sendo língua nacional hegemônica e, por muito tempo, aquela aprendida exclusivamente na escola através de regras gramaticais, impostas a crianças em fase de escolarização, que já precisam lidar com registro e metodologias completamente novos, não é de se espantar que o gosto do cabo-verdiano contraponha-se àquele do português.

A polarização das línguas nasce da própria constituição da nação cabo-verdiana - o crioulo como veículo identitário, de afirmação e oposição ao colono escravocrata mas continua a ser reforçada no meio escolar, quando se busca atingir uma língua portuguesa ideal, imaginária, presente nos livros, mas ausente na oralidade. Trata-se de um desequilíbrio sociolinguístico que não permite mais ampla apropriação linguística nem do português, nem do cabo-verdiano. Se, por um lado, a LM não é institucionalizada como língua de ensino, não se adquire saber metalinguístico, por outro lado, a L2, restringe-se aos contextos estritos de ensino, aprendida de forma pouco espontânea. 


\section{Estatuto das línguas e seu reflexo no processo de ensino-aprendizagem}

Nos estudos sociolinguísticos, percebe-se que questões relacionadas a segurança e insegurança ou atitudes positivas e negativas no momento de se expressar em certa variante têm a ver com a posição, o estatuto dessa variante perante à comunidade linguístico-social. Entendendo que se constata diglossia na atual conjuntura de Cabo Verde, pois os contextos em que se recorre a cada uma das línguas diferem-se (cf. LOPES, 2016; VEIGA, 2007), os jogos de valores sociolinguísticos relacionados ao uso do português e do cabo-verdiano nesta realidade relacionam-se aos estatutos dos idiomas, podendo causar implicações no momento da aprendizagem da L2.

Se admitíssemos que apenas as necessidades comunicativas orientassem as variações linguísticas ${ }^{11}$, o falante tiraria do seu farnel a língua mais apropriada para cada momento, usá-la-ia de bom grado de acordo com o interlocutor, e em seguida voltaria a guardá-la. Ora, ao expressar uma opinião, argumentar, refutar uma ideia, "existe todo um conjunto de atitudes, de sentimentos dos falantes para com suas línguas, para com as variedades de línguas e para com aqueles que as utilizam. (...) As atitudes linguísticas exercem influência sobre o comportamento linguístico" (CALVET, 2002, p. 65).

Ainda, nos diferentes contextos em que cada uma das línguas é utilizada, o nível de escolarização atua fortemente na legitimação social de particularidades fônicas, morfológicas, lexicais ou sintáticas que eventualmente possam emergir. O domínio do “bom português" constitui um dos terrenos para discriminação e exclusão social, muito embora se desconheça propriamente qual seria a norma desse português para a realidade cabo-verdiana.

\footnotetext{
${ }^{11}$ Nomeadamente na concepção que se define a língua apenas como um instrumento de comunicação.
} 
Há alguns debates no sentido de se constatar, no território, a construção de um português próprio, com a perspectiva de constituição de uma variante do português europeu, como defende Brito-Semedo (2010), ao analisar as produções literárias entre os anos de 1842 e 2000:

Ocorreram, desde os primeiros textos publicados em Cabo Verde, três fenômenos linguísticos típicos da comunicação escrita: (i) o fenômeno de se escrever ou só em crioulo ou só em português (período do caboverdianismo); (ii) o fenômeno de se misturar as duas línguas um mesmo discurso, isto é, introduzir palavras e estruturas do crioulo num texto em português (período da cabo-verdianidade); e (iii) o fenômeno da alternância de códigos, ou seja, iniciar a escrita numa das línguas (por exemplo, em português) e passar para a outra língua (nesse caso, o crioulo), ou vice-versa (período do universalismo) (BRITO-SEMEDO, 2010, p. 175).

O universalismo ao qual se refere o autor inscreve-se no período pósindependência da realidade cabo-verdiana, englobando escritores como Corsino Fortes, Arménio Vieira e Silva, ou Danny Spínola. Corsino Fortes, por exemplo, no poema "Pão e fonema" (1974), alterna entre o uso do português e do cabo-verdiano, e ainda recorre a termos que designam conceitos próprios da cultura cabo-verdiana, como guarda-cabeça, funaná, morna, finação ${ }^{12}$. Lopes ainda afirma que:

(...) historicamente, é fortemente previsível que, em vários domínios da gramática, tenha havido mútuas influências, dando origem a uma variedade do português formada em Cabo Verde e, obviamente, a um crioulo de base portuguesa. Na actualidade, o facto de o português ser a língua segunda de muitos cabo-verdianos e de existir um bilinguismo activo concorre para que se mantenham condições favoráveis à mútua influência (LOPES, 2011, p. 37).

\footnotetext{
${ }_{12}$ Interessante notar que as unidades lexicais supramencionadas constam no Vocabulário Ortográfico Comum da Língua Portuguesa, e estão presentes nos Dicionários da Porto Editora, marcados como específicos do léxico cabo-verdiano.
} 
A afirmação de construção de uma variante do português de Cabo Verde é um movimento, contudo, ainda tímido e que carece de mais pesquisas no meio acadêmico $^{13}$. A concepção de língua portuguesa como L2 emergiu inicialmente no ensino superior, impactando metodologias de ensino e de formação de professores, para consequente produção de materiais, embora o aprofundamento da compreensão desse estatuto, por parte da sociedade civil, carece ser reforçado.

Por outro lado, na sequência do Fórum Parlamentar para um bilinguismo social efetivo (Praia - 17 e 18 de maio de 2013), alguns projetos-piloto para uma educação bilíngue começaram a ser implementados no ano letivo de 2013-2014, notadamente por via da pesquisadora Ana Josefa Cardoso, com o projeto intitulado "Si ka fila tudu, ta fila um pónta - Uma experiência de Educação Bilíngue", que defende veemente o ensino formal da LM, argumentando que a assimilação de outras línguas, além de outras áreas curriculares, dá-se comprovadamente de maneira mais eficaz ${ }^{14}$. A linguista Dulce Pereira $(2006,2018)$ sustenta “a maioria das crianças só na escola tem pela primeira vez a oportunidade de tomar a palavra em português"; para a autora, a educação bilíngue permitiria a “aprendizagem da língua portuguesa num ambiente ainda pouco formal, sem abandono da língua de casa e sem os constrangimentos (também para os educadores) das avaliações sumativas que frequentemente inibem a inovação" (PEREIRA, 2018, p. 193).

\footnotetext{
${ }^{13}$ Dos poucos registros nesse sentido, destaca-se o projeto em andamento enquadrado na Cátedra Eugênio Tavares de Língua Portuguesa, de descrição do português de Cabo Verde, integrada, em 2014, à Universidade de Cabo Verde e fomentada pelo Camões: instituto da cooperação e da língua (cf. http://cet-lp.com/index.php/conteudos-geral/11-linha-de-investigacoes/7-linguistica-descritivasincronica-descricao-do-portugues-em-cabo-verde. Acesso em: 16 out. 2019).

${ }^{14}$ Em entrevista ao canal Sapo, a pesquisadora esclareceu que a implementação do projeto aconteceu incialmente em duas escolas básicas da ilha de Santiago (São Miguel, em Flamengos e outra na cidade da Praia, em Ponta d'Água), sendo que após a avaliação do primeiro ano da experiência e "face aos resultados positivos obtidos", no ano letivo seguinte foi estendido a duas escolas do Tarrafal (Santiago) e no ano letivo 2015-2016 ainda duas escolas de São Domingos e duas da ilha de São Vicente foram beneficiadas (cf. https://noticiasdonorte.publ.cv/56300/ana-cardoso-nao-podemos-continuar-fingirnossa-lingua-materna-nao-existe-mante-la-do-sistema-educativo. Acesso em: 16 out. 2019).
} 
Os esforços carecerão, contudo, de provavelmente mais tempo e sobretudo implicação e engajamento políticos para serem recompensados. Em entrevista recente à RTP, no âmbito do programa radiofónico "A Língua de Todos", Cardoso relata o esmorecimento do projeto, por falta de incentivo governamental e efetiva aplicação junto ao Ministério de Educação do país ${ }^{15}$. O valor das línguas, mais uma vez, impõese, direcionando as medidas político-educacionais empreendidas no seio de uma comunidade.

As demandas sociais para uma educação linguística giram-se em torno da aquisição, do desenvolvimento e da ampliação do "conhecimento de/sobre sua língua materna, de/sobre outras línguas, sobre a linguagem de um modo mais geral e sobre todos os demais sistemas semióticos" (BAGNO; OLIVEIRA RANGEL, 2005, p. 63). De acordo com os autores, um dos fatores socioculturais que permite a consecução de tais tarefas consiste no ambiente escolar, onde se encontra uma educação linguística institucionalizada. Uma das funções do letramento ali realizado é a integração do sujeito na sociedade, de forma a estar apto à responder às demandas sociais, como, por exemplo, ter acesso às regras linguísticas padronizadas, sendo capaz de utilizá-las. Contudo, não significa extinguir, apagar ou diminuir algumas das variantes das línguas presentes:

Essas formas padronizadas se vinculam, tradicionalmente, às práticas sociais de letramento mais prestigiadas, e é dever do Estado, e portanto, da escola, garantir que, sem prejuízo de sua variedade de origem, todos os cidadãos possam conhecer e utilizar, conforme lhes pareça conveniente, as formas linguísticas que, por razões históricas, culturais e sociais (e não por supostas qualidades linguísticas intrínsecas), foram erigidas em padrão de comportamento linguístico apropriado às interações sociais mais monitoradas, mais formais, faladas e/ou escritas (BAGNO; OLIVEIRA RANGEL, 2005, p. 78).

\footnotetext{
${ }^{15}$ Em entrevista ao programa de 10 de maio de 2019. Cf. https://www.rtp.pt/play/p393/e406081/linguade-todos. Acesso em: 10 out. 2019.
} 
Com a adoção de uma política educacional linguística orientada ao desenvolvimento escolar sobretudo de uma das línguas presentes na realidade caboverdiana, o sujeito entende que as regras linguísticas são próprias da L2, portanto portadora de conhecimentos mais especializados e sistematizados, enquanto que a LM "não possui regras", sendo sua sistematização impossível por causa das diversas variantes. Essa compreensão controversa da realidade pelo senso comum relaciona-se com medidas políticas defasadas ou ausentes de promoção e valorização das línguas, que reflitam de fato no ambiente educativo. É palpável o conflito entre a variedade "baixa" e aquela "alta", cujo domínio escrito legitima seu lugar na sociedade. Ainda, por ser a "língua dos livros", a variedade "alta", é percebida como homogênea, passível de ser descrita e estudada, contrariamente àquela "baixa", cuja heterogeneidade (mais facilmente perceptível, posto que falada) inviabiliza qualquer tipo de descrição e estudo.

Com o aumento de escolarização e urbanização, espera-se que a exposição ao português abranja mais pessoas. Para tal ampliação, ainda será preciso que haja maior alcance dos meios de comunicação social, difundidos em português; políticas governamentais que orientem o ensino-aprendizagem com o auxílio de metodologias propícias para desenvolvimento linguístico-social; bem como políticas educativas com objetivos claros de difusão do conhecimento, produção e acesso a materiais autênticos que deem conta da realidade sociolinguística do país. Espera-se ainda, de acordo com as instruções ministeriais ${ }^{16}$, que o sujeito cabo-verdiano esteja exposto a línguas estrangeiras, de forma a corresponder a uma sociedade que se desenvolve e se abre para a internacionalização.

\footnotetext{
${ }^{16}$ Nesse sentido, o ministério de educação definiu, em 2017, as seguintes prioridades no seio do ensino fundamental: (i) ensina-se o português, no primeiro ano de escolaridade, como língua segunda (L2); (ii) integram-se as línguas francesa e inglesa a partir do quinto de escolaridade; e (iii) o mandarim é introduzido como língua opcional a partir do nono ano de escolaridade nos subdistritos de Santa Catarina e Praia (ilha de Santiago) e na ilha de São Vicente.
} 
Contudo, ainda afloram propostas de cursos de reforço de português desenvolvidos a nível superior ${ }^{17}$, comprovando que as fragilidades não advêm apenas do conhecimento linguístico, sendo ocasionadas em níveis mais profundos de aprendizagem e interiorização das línguas, com forte influência sociocultural. O reconhecimento legal dos idiomas presentes nesta realidade e o estímulo governamental de práticas educativas bilíngues auxiliaria no processo de conscientização e valoração, impactando positivamente no ensino-aprendizagem. Sibille (2002, p. 7-8), considera que o reconhecimento das línguas pelos atos traduz-se em: (i) responder a uma demanda social; (ii) instaurar o ensino bilíngue ou outras formas de sensibilização às línguas presentes; (iii) incentivar formas de reforço linguístico de manutenção da língua, como equipamentos pedagógicos, dicionários, gramáticas, identificação e recolha dos neologismos; e (iv) ajudar a divulgar os conhecimentos sobre as línguas à população. Dessa forma, a efetiva aplicação da coalfabetização (ou melhor, co-letramento) numa perspectiva bilíngue limitaria os efeitos perversos de atitudes positivas ou negativas face aos falantes, contribuindo para mais ampla apropriação linguística em ambas as línguas.

\section{Considerações finais}

Embora seja imperioso reconhecer alguns dos esforços nacionais e estrangeiros, em graus vários, no desdobramento de ações fomentadoras e instigadoras em prol do conhecimento, da assimilação e apropriação linguísticas na realidade cabo-verdiana, ao atentar à vivência e interpenetração na língua e na cultura que se registra em língua

\footnotetext{
${ }^{17}$ Afloram debates e iniciativas objetivando o desenvolvimento e devido "reforço da língua portuguesa" na realidade cabo-verdiana. Ações são desenvolvidas junto às instituições principais de ensino, nas escolas de ensino fundamental e médio, nas universidades,; nas representações diplomáticas, em especial a brasileira e a portuguesa, por intermédio dos leitorados e dos centros de língua; ou ainda no Instituto Internacional da Língua Portuguesa (IILP), organismo incorporado à CPLP e sediado na cidade da Praia (Santiago).
} 
portuguesa, percebe-se que são circunscritos a momentos específicos de fala e de escrita, atingindo apenas alguns grupos sociais, em geral mais escolarizados.

Por um lado, os espaços alocados ao português são minoritários - restringe-se, em grande parte, na oralidade, a um grupo de intelectuais, caracterizados por atuarem na política, na literatura, no meio acadêmico/escolar ou jurídico, na comunicação social ou ainda nas organizações de caráter internacional. Na escrita, contudo, o domínio da língua é imprescindível em todos os âmbitos, escolar, acadêmico, administrativo, legislativo, o que a qualifica como oficial, contudo, não hegemônica no país. Por outro lado, o domínio da língua cabo-verdiana não acontece de maneira institucionalizada, provocando carência de criticidade e de reflexão metalinguística sobre a própria LM.

A relação que se estabelece entre o aprendiz e cada uma das línguas nasce de uma situação conflituosa, estabelecida pelos valores diferenciados que lhes são atribuídos, que acontece sobretudo a partir do primeiro ano de escolarização. O ambiente escolar evidencia um reflexo dos comportamentos societais em relação à L1 e à L2, muitas vezes reforçando a diglossia já presente nesta realidade. Neste contexto, a falta de reconhecimento e valorização das línguas por parte do Estado de forma efetiva atua negativamente nas percepções da sociedade civil em relação às formas linguísticas prestigiadas e desprestigiadas. Embora haja trabalhos, em quantidade razoável, que centram na situação linguística do país, sobre o ensino da L1 e da L2, ou sobre a descrição da língua cabo-verdiana, tanto nacional ou quanto internacionalmente, dando a entender que o ensino bilíngue adequar-se-ia melhor à situação vivenciada, as tomadas de decisões no plano estatal não se traduzem em políticas e planejamentos linguísticos que os evidenciem.

Dessa forma, as políticas das línguas, calcadas apenas nos valores sociais que se tem sobre elas, silenciam o contexto-fonte do aprendiz, ou seja, de onde ele se alimenta para a sua construção identitária. No contexto-fonte, há o plano linguístico, cuja transferência e interferência acontecem muito frequentemente no contexto-alvo, mas 
outras dimensões, como situacional, interacional, cultural, intertextual e discursiva (KRAMSCH, 1996) atuam no sujeito, refletindo diretamente na aprendizagem. De fato, focando apenas no contexto-alvo, da forma como é ensinada e aprendida a língua portuguesa na realidade cabo-verdiana, esquece-se ou não se considera seu percurso individual e coletivo, bem como todos os processos de interiorização de reflexos culturais próprios do ambiente que circunda o aprendiz.

A escolha de representação das línguas em função dos espaços sociais, da forma como acontece, contribui para cavar o fosso entre os valores da língua majoritária e daquela minoritária, construídos histórica e socialmente, muito embora funcionem em complementaridade (ao menos oficialmente) na sociedade cabo-verdiana.

\section{Referências}

BAGNO, M.; OLIVEIRA RANGEL, E. Tarefas da educação linguística no Brasil. Revista Brasileira de Linguística Aplicada, v. 5, n. 1, p. 63-81, 2005. DOI https://doi.org/10.1590/S1984-63982005000100004

BENVENISTE, É. Problèmes de linguistique générale. Paris: Gallimard, 1966.

BRITO-SEMEDO, M. A contribuição do escritor para o enriquecimento da língua. In: Interpenetração da Língua e Culturas de/em Língua Portuguesa na CPLP. [s.l.] IILP/AULP, 2010. p. 171-176.

CABO VERDE. Constituição (2010). Constituição da República de Cabo Verde. 4 . $^{\text {a }}$



CALVET, L.-J. Sociolinguística. Uma introdução crítica. São Paulo: Parábola, 2002.

CASSIRER, E. La Philosophie des formes symboliques. Tradução: Claude Fronty. Paris: Éditions de Minuit, 1972.

FARACO, C. A. História sociopolítica da língua portuguesa. São Paulo: Parábola, 2016.

FLORY, E. V.; DE SOUZA, M. T. C. C. Bilinguismo: diferentes definições, diversas implicações. Revista Intercâmbio. Revista Intercâmbio, v. XIX, p. 23-40, 2009. 
KRAMSCH, C. Context and culture in language teaching. Oxford: Oxford University Press, 1996.

LÉVI-STRAUSS, C. Anthropologie structurale. Paris: Plon, 1958.

LÉVI-STRAUSS, C. Tristes tropiques. Paris: Union générale d'éditions, 1962.

LÉVI-STRAUSS, C. Anthropologie structurale deux. Paris: Plon, 1973.

LINTON, R. Le Fondement culturel de la personnalité. Tradução: Andrée Lyotard. Paris: Dunod, 1977.

LOMBARD, J. Introduction à l'ethnologie. Paris: Armand Colin, 1994.

LOPES, A. M. As línguas de Cabo Verde. Uma radiografia sociolinguística. Praia, Santiago: Edições UniCV, 2016.

LOPES, F. J. O bilinguismo e a problemática da diglossia no processo do letramento: o caso de Cabo Verde e suas diásporas. Papia 21, v. 1, p. 123-136, 2011.

PEREIRA, D. Crioulos de base portuguesa. Lisboa: Editorial Caminho, 2006.

PEREIRA, D. O cabo-verdiano na educação: implicações no desenvolvimento da língua portuguesa. Atas Jornadas de Língua Portuguesa Investigação e Ensino, p. 183-202, 2018.

POIRIER, J. Ethnologie générale. Paris: Gallimard, 1968.

POIRIER, J. Ethnologie régionale. Paris: Gallimard, 1978.

REVUZ, C. A língua estrangeira entre o desejo de um outro lugar e o risco do exílio. Tradução de Silvana Serrani-Infante. In: SIGNORINI, I. (ed.). Língua(gem) e identidade: elementos para uma discussão no campo aplicado. Campinas, SP; São Paulo: Mercado de Letras; FAPESP, 1998. p. 213-230.

SERRANI-INFANTE, S. O contexto-fonte e o ensino de línguas. Scripta, p. 54-63, 2002.

SEVERO, C. G. A invenção colonial das línguas da América. Alfa, v. 60, n. 1, p. 11-28, 2016. DOI https://doi.org/10.1590/1981-5794-1604-1 
SIBILLE, J. La reconnaissance de la valeur culturelle des langues. La Charte européenne des langues régionales ou minoritaires et la France. Conseil de l'Europe, abr. 2002.

VEIGA, M. Ensino e Aprendizagem das Línguas em meio plurilíngue. Atas do Colóquio Internacional "Ensino/aprendizagem do francês e do português no contexto plurilíngue africano, p. 39-50, 2007.

ZIMMER, M.; FINGER, I.; SCHERER, L. Do bilinguismo ao multilinguismo: intersecções entre a Psicolinguística e a Neurolinguística. ReVEL, v. 6, n. 11, p. 28, 2008. 